\title{
GÉRARD DE NERVAL E A NARRATIVA EXCÊNTRICA. CRÍTICA, FICÇÃO E BIOGRAFIA EM LES ILLUMINÉS
}

\author{
Regis Mikail Abud Filho
}

regismikail@googlemail.com

\section{INTRODUÇÃO: VIDA E OBRA DE NERVAL E LES ILLUMINÉS}

Gérard de Nerval (1808-1855) é um dos representantes mais intrigantes de uma vertente marginal do Romantismo francês. Sua vida foi marcada por crises nervosas e internações em hospitais psiquiátricos que duraram até seu provável suicídio em 1855. Dentre suas obras mais famosas destacam-se Voyage en Orient (1851), que rompe em divertida ironia com as narrativas de viagem, muito em voga em meados do século 19; Les chimères (1854), coletânea de poesias impregnadas de ocultismo e misticismo; Sylvie (1854), novela louvada por Proust em Contre SainteBeuve devido a seu caráter onírico, assim como a narrativa póstuma Aurélia (1855), de grande influência para os surrealistas. Nerval escreveu também peças de contos, artigos e peças de teatro. Somente a partir da segunda metade do século 20 a obra de Nerval passa a suscitar crescente interesse da crítica literária, que até então o considerava um autor menor devido ao seu estilo fragmentário e pouco ortodoxo.

Les Illuminés (1852), o texto que abordaremos aqui, é uma coletânea de estudos escritos por Nerval entre 1839 e 1851, publicados em diversos jornais. Dentre suas obras, é provavelmente a mais incompleta e a de estrutura menos evidente. Nerval retrabalhou estes retratos literários 
"excêntricos" antes de incluí-los nesta antologia aparentemente pouco clara e caótica, motivo pelo qual permanece pouco estudada. Apenas dois grandes estudos científicos foram dedicados exclusivamente a Les Illuminés como um todo: Critical fictions. Nerval's "Les Illuminés" de Meryl Tyers (1998) e o recente estudo de Keiko Tsujikawa, Nerval et les limbes de l'histoire (2008). Neste último a autora analisa de modo convincente e detalhado este "livre parfaitement sensé sur des folies" (MILNER, 1990, p. 464-471) justamente a partir de seu caráter fragmentário e híbrido.

"La bibliothèque de mon oncle" é o único texto escrito exclusivamente para Les Illuminés. Este curto prefácio, no entanto, mais confunde do que esclarece a proposta desta compilação. Seguem os seis estudos, respectivamente, sobre as seguintes figuras históricas ao longo dos séculos: Le roi de Bicêtre: Raoul Spifame (XIVe siècle); Histoire de l'abbé de Bucquoy (XVII siècle); Les confidences de Nicolas (XVIII ${ }^{e}$ siècle); Jacques Cazotte; Cagliostro (XVIII siècle) e Quintus Aucler: République française, La Thréicie. ${ }^{1}$ Procuraremos aqui mencionar os aspectos principais no tocante ao sincretismo textual de Nerval sem ater-nos muito a explicações detalhadas sobre a biografia de cada illuminé.

Nerval utiliza processos intertextuais como citações, palimpsestos e pastiches em um jogo literário de claro e escuro no qual esboça sua autobiografia - projeto latente que nunca realizará efetivamente ${ }^{2}-a$ partir da biografia do outro. Procuraremos abordar aqui como a fronteira entre gêneros em Les Illuminés é relativizada, compondo uma "narrativa excêntrica”. Trata-se, portanto, de uma obra rapsódica, fortemente inspirada pela literatura de Sterne e Diderot, repleta de metalepses e digressões aparentemente desconexas. Procuraremos mostrar aqui a composição desta excentricidade textual, na qual gêneros como o ensaio, a ficção e a biografia se entrelaçam. De acordo com Daniel Sangsue, "[a] excentricidade vem à tona a partir do caráter rapsódico da narrativa, da composição bizarra que alterna narrativa, diálogos, digressões, interrupções [...]" (SANGSUE, 1987, p.29). Tendo em vista tal hibridismo,

1 Os textos de Nerval aqui mencionados correspondem à nova edição da Pléiade de 1984.

2 Resumidamente tentaremos esclarecer tais técnicas intertextuais segundo Michel Schneider, em seu Voleur de mots, publicado em 1985: o plágio consiste sobretudo em uma questão jurídica, cuja história se mostra ora tolerante, ora condenadora de tal prática; o palimpsesto é uma espécie de reescrita do documento original de um texto sobre o texto original apagado; o pastiche, por sua vez, é um exercício literário, uma retomada estilística de outros autores, sobretudo de suas sintaxe e léxico. Neste artigo nos ateremos principalmente ao palimpsesto por questões de espaço. 
pode-se dizer que Nerval elimina do ponto de vista da teoria da recepção os horizontes de espectativa de tais gêneros (como já o fizera em seu Voyage en Orient). Elementos fictivos penetram na biografia e vice-versa; crítica literária e digressões são intermitentes na intriga narrativa.

Abordaremos aqui três pontos principais em Les Illuminés: os confrontos entre biografia/autobiografia e ensaio/ficção; o conceito de contradiscursividade poética no texto literário; e os procedimentos intertextuais como a citação, o palimpsesto e o pastiche.

Assim como nos poemas de Les Chimères (1854), trata-se em Les Illuminés de um jogo no qual prevalece a mutabilidade de sentidos. Considerando a contradiscursividade iminente do texto, leva-se em conta a inegável "art d'accomoder des restes" de Nerval (STREIFF-MORETTI, 1991, p. 101), bem como o "caractère de seconde main" de sua obra, inseridos em uma espécie de contra-história:

\footnotetext{
“ [...] a variedade, a disparidade, a excentricidade ou simplesmente o acaso parecem ter determinado esta escolha ou estas associações. Mas é talvez justamente nesta desordem aparente que reside o caráter mais inovador do pensamento de Nerval sobre o tempo e a história” ${ }^{3}$
}

Embora tal aspecto esteja presente em boa parte da obra de Nerval, ela se mostra de maneira acentuada nesta antologia, que parece deixar a pergunta aberta de como seria a história atual se os projetos políticoreligiosos estrambólicos destes excêntricos se tivessem realizado. Assim, são apresentadas as idéias monarquistas reacionárias de Cazotte, da mesma maneira que o pensador Quintus Aucler sugere o fim do cristianismo, propondo um retorno ao paganismo nas respectivas narrativas homônimas. Outros exemplos são as revoltas desconhecidas contra o Absolutismo em Histoire de l'abbé de Bucquoy e os projetos legislativos bizarros do esquizofrênico Raoul Spifame (Le Roi de Bicêtre). Ao restaurar tais retratos literários de pensadores esquecidos pelo tempo (à exceção de Cagliostro, Cazotte e Restif), Nerval escreve uma História subterrânea, quase completamente ignorada pela História normativa vigente, colocando em questão a História que poderia ter acontecido, procurando simultaneamente espelhar tal excentricidade na forma do texto literário.

3 [...] la variété, la disparité, l'excentricité ou tout simplement le hasard, semblent avoir présidé à ce choix ou à ces associations. Mais c'est peut-être précisément dans ce désordre apparent qui réside le caractère le plus novateur de la pensée nervalienne du temps et de l'histoire." (ILLOUZ, in TSUJIKAWA, 2008, p. IX-XX) 
O leitor percebe então uma evidente identificação entre Nerval e seus illuminés, relatando (não sem uma certa fantasia) fatos e motivos literários já presentes em sua obra. Um destes motivos é o motivo do duplo, presente em Le Roi de Bicêtre, simbolicamente representado no momento em que o protagonista Raoul Spifame se olha no espelho, crente de ser o Rei Henrique II. O mesmo ocorre em Les confidences de Nicolas, retrato volumoso e detalhado do escritor Restif de la Bretonne. Ali Nerval se apropria da biografia de Restif, modificando-a de acordo com sua própria autobiografia, embora ele se proponha - em princípio - a escrever a biografia de Restif. Outra forte identificação literária pode ser notada em Cazotte, narrativa na qual Nerval louva a literatura onírica e leve (légère) de Jacques Cazotte, da qual ele toma elementos emprestados, prenunciando a poética do sonho que culminará em Aurélia. Desta maneira, Nerval se insere na genealogia destes excêntricos, adicionando a suas biografias algumas anedotas históricas de uma historiografia marginal, não mencionada "oficialmente", bem como elementos fictivos e "intrusões" autobiográficas.

Ao ser publicado, Les Illuminés ganhou dois subtítulos: Les précurseurs du socialisme na capa e Récits et portraits na contracapa. Embora o título e o subtítulo de Les Illuminés se mostrem problemáticos e evoquem significados religiosos, sobretudo no que diz respeito à seita dos iluministas, esta última não aparece em todos os textos. Além disso, nenhum dos seis personagens pode ser considerado estritamente iluminista. Nerval representa uma enorme variedade de religiões e crenças, ao misturar paganismo e cristianismo, revelando como ambos eram originalmente semelhantes (a exemplo da cerimônia carnavalesca de Cagliostro e da já mencionada reforma religiosa proposta por Quintus Aucler). Tal sincretismo se espelha também na própria estrutura textual de Les Illuminés. Ora, a pluralidade religiosa de Nerval - lembremos de sua declaração a Gautier sobre ele "ter no mínimo dezessete religiões" (GAUTIER, 1867, p.57) - correspondeà sua flexibilidade literária no tocante aos gêneros e à subversão destes. É preciso propor, portanto, uma nova abordagem de Les Illuminés; uma abordagem que não seja parte de uma análise psicanalítica, nem historiográfica eque tampouco consista na busca da crença religiosa em Nerval, tarefa árdua na qual muitos se aventuraram sem aparente sucesso. Ao invés disto, parece-nos mais adequado propor uma leitura crítica do ponto de vista da composição literária, e não tentar compreender suas crenças sincréticas nem diferenciá-las umas das outras em busca de coerência. Ademais, deve-se levar em conta que Nerval, apesar de sua ampla cultura sobre as religiões, não é teólogo, mas escritor. Logo, uma análise estrita do ponto de vista religioso de Les Illuminés se 
mostra insuficiente, já que Nerval joga com a transitividade dos sentidos destes elementos místicos, religiosos e mitológicos, subvertendo muitas vezes seu sentido original a serviço de uma poética que se remete à tecnica da colagem. Sequer as opiniões políticas de Nerval são claras.

Nerval trabalha com aspectos históricos esquecidos, mas de certa forma importantes por representarem uma oposição à ordem vigente, oposição essa que se espelha no procedimento contradiscursivo do texto nervaliano: em meados de um século XIX que preza a originalidade da obra de arte, Nerval parece provocar tal mandamento, ainda que sutilmente, por meio de seus procedimentos intertextuais. A própria inserção de personagens fictícios nos estudos (ou "analyses", como ele próprio define) representam uma contra-história que funde fantasia e realidade, biografia e ficção. Nerval não cai no gênero romanesco, mas também não escreve ensaios íntegros nem historicamente verdadeiros, produzindo assim um texto híbrido. Por exemplo: o romance de folhetim (roman-feuilleton) é ironizado no pré-texto aos Faux saulniers - a Histoire de l'abbé de Bucquoy de Les Illuminés - no qual Nerval se propõe a escrever um "feuilletonroman" ao invés do então popular "roman-feuilleton." O próprio Nerval afirma-se como excêntrico, sobretudo ao digressionar e suspender a narrativa, não pela técnica vulgar que faz aumentar a expectativa do leitor, mas sim para criticar a Lei Riancey, que proibia a publicação de romances históricos sem documentação ou baseamento históricos sob pena de multa. Devendo, portanto, corroborar historicamente tudo o que escreve, Nerval vê-se obrigado a escrever sobre outros assuntos que não a vida do Abbé de Bucquoy, pois não encontra documentos sobre este. Nestes momentos, acaba por falar de si mesmo (daí o aspecto autobiográfico "intruso"), contando historietas singelas e inserindo máximas populares, não sem sua ironia característica.

A partir de uma perspectiva histórica, Nerval exprime suas decepções com as revoluções burguesas incompletas de meados do século 19, cujo fervor violento ele critica, assim como Cazotte criticara os "temples de la raison" (NERVAL, 1852, p.1094-1095) que a Revolução Francesa queria construir. Deste sentimento surge em Nerval o desejo de descrever estes excêntricos e suas idéias. A história marginal encontra-se sobretudo na biblioteca do tio mencionada no prefácio, uma espécie de não-lugar como a Biblioteca de Babel imaginada por Borges, repleta de saberes acumulados, onde Nerval absorve uma "nourriture malsaine" dos "fouillis des siècles“ (NERVAL, 1852, p.885). Que curso teria tomado a História se a legislação bizarra proposta por Raoul Spifame fosse posta em prática ou se Cazotte não tivesse sido executado pelos revolucionários devido a suas 
idéias monarquistas? E se o comunismo peculiar (e altamente discutível) de Restif se tivesse estabelecido?

O humor também desempenha um papel interessante, sobretudo em Cagliostro, cujo charlatanismo cerimonioso do personagem homônimo é evidente. Trata-se de um texto majoritariamente composto por passagens inteiras citadas (mas não declaradas) dos relatos de Luchet, donde se pode concluir que Nerval se identifica com o charlatanismo de Cazotte através de plágios de seus textos, aqui propositalmente executados. Nerval explica como as seitas secretas estão interligadas e se referem umas às outras, modificando-se. O próprio cristianismo é impregnado de elementos pagãos. A política e a religião também eram inseparáveis. A partir destes aspectos, Nerval procura construir um texto literário cuja forma espelhe uma união com o passado através de tais técnicas intertextuais.

Outro exemplo de "charlatanismo literário" e de temática religiosapagã é tratado por Nerval em Quintus Aucler, no qual uma possível simpatia pela inimaginável volta do paganismo proposta por Aucler transparece. Desta maneira Nerval critica os caminhos políticos de sua própria época, na qual as religiões tendem a cair em esquecimento. Contra isto, ele mostra a que ponto o discurso político está impregnado do discurso religioso. Embora a simpatia de Nerval por Aucler não esteja claramente formulada, as citações volumosas da Théicie de Quintus Aucler são um indício para isto, pois este procedimento faz com que Nerval se aproprie sutilmente da voz narrativa de Aucler após extensas citações. Apesar da morte das religiões, Nerval expressa discretamente - e com um certo tom de desespero - seu desejo de pertencer a uma crença. No final de Quintus Aucler ele escreve: "[...] tout illuminé peut avoir des communications [...]" (NERVAL, 1852, 1161). Do ponto devista da intertextualidade, Nerval mostra aqui que tais comunicações não são simplesmente as correspondances no sentido místico de Swedenborg. Elas são também, polissemanticamente, uma realidade textual: Nerval corresponde-se com seus illuminés através de citações, plágios, palimpsestos e pastiches. As religiões e seus templos se estabelecem uns sobre os outros (a exemplo da Igreja de Saint-Denis mencionada em Quintus Aucler, construída sobre tempos pagãos), seguindo uma linha de continuidade através da reconstrução, o texto literário é por si só um palimpsesto, no qual as passagens são apagadas, justapostas e/ou modificadas. Assim como a destruição do templo pagão sobre o qual foi construída Saint-Denis, o texto literário em Les Illuminés também destrói para reconstruir. Trata-se de uma homenagem: "Qu'importent les tombes brisées et les ossements outragés de SaintDenis ! La haine leur rendait hommage." (NERVAL, 1852, p. 1136) 
Há ainda uma outra polissemia reveladora em Les Illuminés: o termo "socialisme", presente no subtítulo. Ao contrário do que parece ser inicialmente sugerido, nem todos os personagens estão politicamente engajados no movimento socialista da época. Na verdade, cada um destes personagens reais tem projetos políticos e religiosos bastante peculiares. ${ }^{4}$ E é justamente este o tema principal dos Illuminés: a inseparabilidade e a origem comum da religião e da política, do paganismo e do cristianismo. Nerval parece querer traçar em Les Illuminés um fio condutor que remeta a um estado original pagão, quando ambas eram indissociáveis. Neste caso, é mais plausível considerar a hipótese da ironia nervaliana na escolha do título. De fato, as personagens não são pintadas por Nerval sem paradoxia, ironia ou humor. Desta maneira, ele compôs uma obra cujo caráter político-religioso é polissemanticamente carregado.

Uma possível identificação de Nerval com o excentrismo dos illuminés retratados é demonstrada através de palimpsestos de textos destes autores, em que Nerval mistura ficção a crítica literária. Por isto, é fundamental esclarecer seu modus operandi literário: pré-textos são aqui pretextos para um processo excêntrico e fascinante.

\section{BIOGRAFIA, AUTOBIOGRAFIA E FICÇÃO: A PERFORMATI- VIDADE DOS GÊNEROS}

O problema da tensão entre biografia e autobiografia permeia Les Illuminés do começo ao fim. Já em uma das primeiras recensões escritas, denominou-se "autobiographie déguisée" ou "autobiographie d'un autre" (MARIE, 1929, p. I, XXXI). Em Les Illuminés, isto é só um aspecto do todo:é preciso abordá-lo como um livro uno e intratextual, cuja performatividade da própria escrita é o aspecto principal.

Em Les Illuminés existe uma referência autobiográfica evidente já desde o início: o "eu" auto-referente do prefácio. Devido a alterações

4 Em uma carta a Émile de Girardin, Nerval escreve: "Je vous envoie mon dernier livre. Je n'ai pas besoin de vous avertir qu'il y a quelque ironie dans la préface sur ce sujet semi-politique du socialisme - à moins que vous ne lisiez pas l'ouvrage". Em uma carta a Jules Janin, anterior à de Girardin, Nerval havia, porém, confirmado a referência ao Socialismo em Les Illuminés: "Je vous promets Les Illuminés qui vont paraître et contiennent plusieurs biographies curieuses de précurseurs du socialisme actuel." A relação entre as seis personagens desta antologia e a seita dos iluministas permanece questionável, apesar do título, à exceção de Cazotte, envolvido com o martinismo. A primeira carta se encontra no Volume 2 das obras completas de Nerval, publicada pela Pléiade, nas páginas 1307-1308. A segunda, no Volume 1, p. 2045. 
em alguns fatos biográficos das personagens e a inserção de sua própria biografia neles, podemos considerar Les Illuminés também como uma "biografia autobiográfica". Ora, seria possível, de maneira geral, considerar o gênero biográfico como totalmente isento da autobiografia do biógrafo? A biografia não estaria sujeita à linguagem deste último, e portanto, fadada à subjetividade deste?

A exemplo de Le Roi de Bicêtre, coexistem na narrativa personagens reais, como o rei Henrique II e Raoul Spifame, e personagens fictícios como o companheiro de cela de Spifame, Claude Vignet, auto-denominado Claudius Vignetus. Com esta fusão de realidade e ficção, além de elementos da intriga romanesca inventados por Nerval identifica-se aqui uma espécie de extensão do procedimento utilizado no romance histórico de Walter Scott e Dumas. Entretanto, Les Illuminés difere deste gênero por suas digressões, bem como por suas longas citações e pastiches. Tais procedimentos não são frutos de uma "desonestidade" literária da parte de Nerval, mas representam sobretudo um primeiro passo para a dissolução de modelos miméticos, apontando para uma metarepresentação da escrita, sendo esta performativamente encenada.

Considerar os seis estudos como ficção pura parece no mínimo problemático, pois trata-se não apenas de uma inserção da biografia na ficção, mas também da inserção da ficção na biografia. Tampouco podem ser considerados textos biográficos. Por "ficcionalidade" entende-se aqui um contrato segundo o qual a pretensão da verdade não está inserida na realidade "verdadeira", palpável, mas sim na verdade imaginária de um mundo narrado, ou seja, verossímil em sua diegese - o que ocorre em Les Illuminés. A partir do momento em que personagens fictícios everdadeiros são situados no contexto de um passado histórico, este contrato de ficção perde sua validade. Por que, então, não considerar Les Illuminés como críticas ficcionais ao invés de ficções críticas (critical fictions, como propõe Tyers)? Les Illuminés não consiste, portanto, stricto sensu, em uma autobiografia, nem em ensaios. Tampouco se trata estritamente de biografias ou de ficção.

De acordo com a crítica recente, romance e biografia são gêneros correspondentes e entrelaçados (EGELHAAF-WAGNER, 2005, p.5).5 É

5 "Por fim, aceita-se na discussão autobiográfica mais atual que o momento da ficção não se opõe ao desejo de auto-expressão, mas que se realiza ao contrário naquela relação do eu e do mundo como uma relação ficcional, produzindo a ficção com isso então a realidade autobiográfica." A tradução é de minha autoria, conforme o original: "Schließlich wird gerade in der jüngsten Autobiografiediskussion geltend gemacht, dass das Moment der Fiktion dem Begehren nach Selbstausdruck keinesfalls entgegenstehe, 
possível considerar, portanto, ambos como complementares um ao outro, pois no texto autobiográfico encontram-se também passagens ensaísticas e críticas, assim como a biografia de outras pessoas (EGELHAAFWAGNER, 2007, p.7). Este é um dos motivos pelos quais Les Illuminés não se deixa "decifrar", de modo que o sentido textual nervaliano transcende e se modifica, como Streiff-Moretti explica em seu ensaio Nerval: L'autre discours (STREIFF-MORETTI, 1991).

Como os textos não se encaixam em nenhuma categoria, o que se destaca no texto é a escrita "pura", em sua performatividade, ou seja, em sua forma de expressão como parte do texto literário, nomeadamente $o$ ato de escrever como ação. Egelhaaf-Wagner explica:

"É exatamente a partir deste dilema que o texto biográfico é percebido como contraste e como função de uma realidade fora do texto; a partir do confronto entre referência e performance literária resulta a posição literária peculiar da autobiografia: sua proximidade ao romance e o fato de que, por fim, um texto autobiográfico como tal não pode se diferenciar de um romance em primeira pessoa. Desta maneira, existem vários romances, que se travestem de autobiografia."

Contudo, no século 19 as biografias eram ainda consideradas gêneros "neutros" no tocante à verdade. Além disso, o conceito de objetividade histórica já é por si só discutível, sobretudo em obras literárias. Estas não são mesuráveis nem verificáveis pelo fato estarem sempre submetidas a uma vivência pessoal, assim como a escrita biográfica e autobiográfica. No entanto, podem-se encontrar os chamados "horizontes de expectativas", tanto no gênero (auto)biográfico quanto nos textos de ficção. Esteelemento compõe já o primeiro estranhamento do leitor perante os Illuminés: esperam-se biografias que façam referências ao socialismo e à seita dos iluministas. Estes horizontes dizem respeito também à declaração de Nerval no prefácio, em que ele suplanta a taxonomia banal de gêneros: Nerval apresenta seus retratos como "analyses", "études", de modo que este

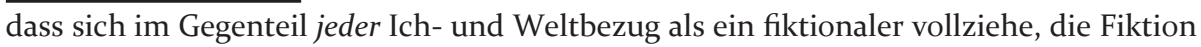
mithin erst die autobiografische Realität produziere."

6 Tradução minha, conforme EGELHAAF-WAGNER, 2005, p.4: „Aus genau diesem Dilemma, dass der autobiographische Text auf der Folie und als Funktion einer außertextuellen Realität wahrgenommen wird, aus dem Widerstreit zwischen Referenz und literarischer Performanz resultiert die eigentümliche literaturwissenschaftliche Position der Autobiographie: ihre Nähe zum Roman und die Tatsache, dass ein autobiographischer Text als solcher letztlich von einem Ich-Roman nicht zu unterscheiden ist. So gibt es nicht wenige Romane, die sich in das Gewand der Autobiographie kleiden $\left.[\ldots]^{\prime \prime}.\right)$. 
pressuponha um certo compromisso com a esperada "realidade" prevista por um modelo normativo.

O gênero biográfico situava-se em uma posição central na França daquela época, onde prevalescia um interesse semi-científico por publicações como retratos literários, além de enciclopédias e fisiologias (TYERS, 1998, p.4). Os estudos de Les Illuminés ironizam esta exigência de neutralidade, tema que Nerval já explorara em Les faux saulniers/Histoire de l'Abbé de Bucquoy ao driblar a lei que exigia veracidade histórica e provas documentais na produção literária de narrativas históricas. Nestas duas narrativas textualmente muito próximas (a primeira foi publicada à parte e a segunda foi posteriormente inserida em versão reduzida em Les Illuminés), o autor procura estabelecer um jogo entre o documentado e o imaginado. Desta relação, entra em jogo a ficção nestas "análises", o que confere hibridismo à obra.

A aventurosa circulação por gêneros literários é de fato considerável nas últimas fase de Nerval, da qual Les Illuminés faz parte. Esta coletânea chegou inclusive a ser posteriormente publicada em edições junto a Les Filles $d u$ feu. A relação entre estes dois textos é reveladora: Jean-Nicolas Illouz considera Les Illuminés como "les fils du feu" (in TSUJIKAWA, 2008, p. XIII), em um pertinente e revelador jogo polissemântico: De um lado, o sentido do já mencionado "fil conducteur", que liga um illuminé ao outro; do outro lado o sentido dos illuminés como filhos ("fils"), aparentados uns aos outros. A moda dos retratos literários do século XIX é ironizada por Nerval já na própria escolha dos modelos para seus retratos: estes não são cânones, mas em sua maioria, literatos marginais. Igualmente irônica é a maneira excêntrica de escrever este gênero, tão em voga na época. Tal procedimento, típico do anti-roman, é por si só contradiscursivo.

\section{CONTRADISCURSIVIDADE POÉTICA}

Les Illuminés foi apontado como um livro confuso e frouxamente conexo ao ser publicado. Nerval problematizou não apenas as referências históricas, mas também as próprias formas de representação que aparecem como exemplo de "literatura excêntrica", gênero largamente aceito na tradição literária.

Daniel Sangsue menciona a respeito da forma textual da literatura excêntrica uma "nova leitura que tende a considerar o texto como um mosaico-rapsódia-marchetaria de acabamento artificial e a levar seus efeitos de linearidade e de completude à falência." (SANGSUE, 1987, 
p.12). O excesso de excentricidade de Les Illuminés evidencia o aspecto contra-histórico e contradiscursivo desta obra, questionando sobretudo as técnicas poéticas do século XIX como já se vira em Voyage en Orient:

\begin{abstract}
"Assim, no final do último parágrafo de Voyage en Orient de Nerval é lançada uma pergunta para discussão que ultrapassa os limites da época, à qual este texto e sua forma de gênero devem sua existência: se aquele híbrido de 'réel' e 'rêve' que encena discursos românticos não convence mais, como deve ser constituída, então, a narração de um 'réel' igualmente interessante como um sonho, que deva renunciar totalmente a um apoio factual?" (KÜPPER, 1999, p. $252)^{7}$
\end{abstract}

A fim de esclarecer esta oposição entre sonho e realidade, é preciso tratar da questão do discurso literário em Les Illuminés. De acordo com Foucault, a grosso modo, os discursos são sistemas de enunciados, que resultam de certas práticas institucionais, como a Medicina, a Biologia, a Teologia, o Direito, etc. e definem a correlação linguística de tais práticas (FOUCAULT, 1969). A fim de melhor explicar a contradiscursividade em Les Illuminés, tomaremos aqui a posição de Rainer Warning (que por sua vez desenvolve o conceito de "contradiscursividade" primeiramente cunhado por Foucault), segundo a qual o discurso literário não é um discurso independente, tampouco ponto de cruzamento ou de encontro entre discursos diferentes. Embora Foucault perceba que formas de saber possam entrar em textos literários, ele não considera o discurso como um "caldeirão" de discursos diferentes:

“Os territórios arqueológicos podem atravessar textos 'literários' ou ‘filosóficos' assim como textos científicos. O saber não é investido somente em demonstrações; ele também pode sê-lo em ficções, em reflexões, em narrativas, em regulamentos institucionais, em decisões políticas."

7 Tradução de minha autoria, conforme o original: "So steht am Ende der ersten Abschnitte von Nervals Voyage en Orient eine Frage zur Diskussion, die über die Grenzen der Epoche hinausweist, der dieser Text und seine Gattungsform die Existenz verdanken: Wenn jene Hybride von 'réel' und 'rêve', die romantische Diskurse inszeniert, nicht mehr überzeugt, wie muß dann die Schilderung eines réel beschaffen sein, das gleichwohl interessant ist, wie ein rêve, der auf einen Gegenhalt im Faktischen ganz verzichten muß?"

8 "Les territoires archéologiques peuvent traverser des textes 'littéraires' ou 'philosophiques' aussi bien que des textes scientifiques. Le savoir n'est pas investi seulement dans des démonstrations, il peut l'être aussi dans des fictions, dans des réflexions, dans des récits, dans des règlements institutionnels, dans des décisions politiques." (FOUCAULT, 1969, p. 248). 
Para Warning, não se deveria falar em "discurso literário" (pois segundo ele - em referência a Foucault -, tratar-se-ia sobretudo de uma subversão dos discursos de tais saberes institucionais). Partindo desta teoria, Warning desenvolve o conceito de contradiscursividade poética ("contre-discours" 9 ). Ele mostra o quão longe os textos poéticos distam de outros discursos, de modo que à literatura seja imputado um certo "estatus especial" (Sonderstatus), em que o discurso das formas de saber são evocados ao ser subvertidos. Daí pode-se falar de uma dialética de inserção e exclusão:

"Pois somente então esta dialética pode responder à pergunta de que maneira
a literatura se insere afirmativamente em contextos discursivos, dos quais ela
se distancia ou nega, e como esta tomada de distância ou negações pode ser
abordada mais de perto, tanto do ponto de vista estrutural quanto do ponto de
vista funcional." (WARNING, 1999, S. 318 ) $^{10}$

Quanto à estrutura textual, pode-se dizer que as extensas citações e os palimpsestos que Nerval faz de outros textos corroboram tal aspecto contradiscursivo (de grandes passagens ou observações pontuais, que podem coincidir com a citação original, até modificações declaradas e não-declaradas de pré-textos), desafiando assim a primazia romântica da originalidade.

Para citar outro exemplo de contradiscursividade em Les Illuminés, podemos citar os exemplos de Cazotte, Cagliostro e Quintus Aucler, nos quais Nerval critica a radicalização da Revolução Francesa servindo-se do tom inflamado, quase religioso dos revolucionários céticos, a fim de criticar as próprias incoerências das Revolução de 1848. Nerval parece argumentar que o discurso religioso provém da mesma origem que o discurso político; isto em uma época em que a radicalização da Revolução Francesa é reevocada com o intuito de eliminar a religião da política nas

9 Warning cita a seguinte passagem de Les mots et les choses : „Or, tout au long du XIX ${ }^{\mathrm{e}}$ siècle et jusqu'à nous encore - de Hölderlin à Mallarmé, à Antonin Artaud -, la littérature n’a existé dans son autonomie, ne s'est détachée de tout autre langage par une coupure profonde qu'en formant une sorte de "contre-discours", et en remontant ainsi de la fonction représentative ou signifiante du langage à cet être brut oublié depuis le XVIe siècle." (In Les mots et les choses, Gallimard, Paris, 1966, S. 58).

10 Tradução minha, conforme o original: "Denn nur und erst diese Dialektik kann Antwort geben auf die Frage, in welchem Maße sich Literatur affirmativ einfügt in diskursive Kontexte, wo sie sich von ihnen distanziert oder sie negiert und wie diese Distanznahmen oder Negationen strukturell wie funktional näherhin zu fassen sind." Como exemplo de textos contradiscursivos, Warning cita e analisa inclusive o discurso religioso do Renascimento em Dante e Petrarca até autores do século XIX como Balzac e Flaubert. 
então recentes lutas de 1848, marcadas pela cisão definida entre crença e ceticismo. Curiosamente, é justamente em momentos de descrença espiritual que o misticismo e o ocultismo penetram em momentos (MARIE, 1929, p.1).

Nerval relativiza assim a historiografia "oficial" ", dando lugar a seus excêntricos marginais, que de certa forma correspondem à tentativa de Nerval de refutar as limitações de um tempo linear e de inverter a história diacrônica (TYERS, 1998, p.14). Tsujikawa explica esta relação:

\begin{abstract}
"Nerval se debruça sobre o sentido e a série da ruptura operada pela Revolução Francesa. Ele procura também encontrar uma filiação subterrânea com o século 18 -, que poderia ajudar a superar as fraturas históricas aparentes. Ele se esforça, em suma, para remediar o desencanto do século 19 e para preservar a possibilidade de uma renovação espiritual para o futuro. Suas interrogações tornam-se mais insistentes no meio do século, e elas são abordadas diretamente em Les Illuminés ou les précurseurs du socialisme"12.
\end{abstract}

Tsujikawa demostra ainda o quão impregnados de historicismo são os retratos feitos por Champfleury, que ao contrário dos retratos de Nerval, estão inseridos completamente nos moldes estético-literários de sua época. Champfleury cita, assim, o discurso da Medicina como uma espécie de corroboração para seu texto, ao passo que Nerval, ao descrever as idéias políticas e religiosas de seus excêntricos, as cita criticamente, ou as copia e altera, imputando novo significado a estes discursos e desta maneira questionando-os (TSUJIKAWA, 2008, p.128). Pode-se concluir, então, que a produção literária de Nerval é tão pouco ortodoxa quanto sua crença religiosa.

\title{
CONCLUSÃO: POLISSEMIAS, POLÍTICA E RELIGIÃO
}

O fio condutor dos Illuminés consiste não apenas na excentricidade ou em projetos insanos, mas igualmente em no aspecto intertextual dos

11 Vide o prefácio de Guy Duprés para uma edição de 1992 de Les Illuminés, in DUPRÉ, Guy, Les Illuminés ou les précurseurs du socialisme, Éditions du Rocher, Monaco, 1992, p. 7-44).

12 Nerval se penche sur le sens et la portée de la rupture opérée par la Révolution française. Il cherche aussi à retrouver une filiation souterraine avec le XVIIIe siècle, qui pourrait aider à dépasser les fractures historiques apparentes. Il s'efforce enfin de remédier au désenchantement du XIXe siècle et de préserver la possibilité d'un renouveau spirituel pour l'avenir. Ces interrogations se font plus insistantes au milieu du siècle, et elles sont posées de manière frontale dans [...] Les illuminés, ou les Précurseurs du socialisme." (TSUJIKAWA, 2008, p.3). 
“empréstimos literários” deNerval.Atravésdatextualidadecontra-histórica e contradiscursiva Nerval pinta e "restaura velhas telhas" (NERVAL, 1852, p.885) com leveza graciosa e humorística, evocando a maneira fabulosa de Cazotte e as bizarras utopias românticas de Restif. Estes retratos parecem contestar a forma vigente dos "portraits et analyses" de sua época. Não se pode, portanto, concordar com o termo "daguerreótipo", utilizado pelos imãos Goncourt para definir Les confidences de Nicolas: "Este estudo, que toma Restif quase em seu nascimento e o conduz à sua morte é um dos daguerreótipos literários mais encantadores que já existiram.” (GONCOURT, in TYERS, 1998, p. 39). Os retratos de Les Illuminés tendem mais a se parecer com uma "lanterna mágica", expressão que Nerval utiliza para designar o projeto autobiográfico de Restif: "[Restif] a eu l'idée bizarre de représenter, comme dans une lanterne magique, les scènes principales de son existence" (NERVAL, 1852, p. 956). Ou seja, preferir-se-á a metáfora da lanterna mágica devido a seu caráter fantasioso e indefinido, quase disforme à pretensa realidade almejada pelo daguerreótipo. A respeito de Les Illuminés de maneira geral, pode-se pensar também em uma forma parecida de representação: Nerval expõe seus retratos sem descrever o real, se é que este é possível dentro dos gêneros biográfico e autobiográfico. Como o operador da lanterna mágica, ele apresenta uma imagem destas figuras construída por ele próprio, representando suas biografias à sua própria maneira. Nerval lança um novo olhar sobre estes personagens marginais da história, em uma estranha oposição: sua originalidade reside justamente em desafiar o prezado conceito de originalidade do século XIX. O leitor é convidado a compreender História e écriture através de suas facetas escondidas e não-lineares. Quanto à unidade de Les Illuminés pode-se afirmar que ela provém da própria descontinuidade delirante, indicada já no prefácio: "Que devait-on faire avant de lire?" (NERVAL, 1852, p. 886) Com isto ele propõe uma espontaneidade performativa, que se aproxima do delírio, como Tyers nota no jogo polissemântico: de lire / délire.

De acordo com as teorias de Swedenborg, as já mencionadas correspondances consistiriam basicamente em correspondências entre as partes físicas do corpo com certas partes na alma. Neste contexto, o sonho desempenha um papel essencial, a exemplo da narrativa Cazotte, na qual Nerval descreve um sonho premonitório do protagonista, no qual os contra-revolucionários são decapitados. Tal sonho acaba por revelar-se verdadeiro. Porém, é impossível ler Les Illuminés tendo em vista uma interpretação imediata deste conceito swedenborguiano; tratase sobretudo de um jogo polissemântico, já anunciado no título, a ser 
mais amplamente compreendido. Se Nerval supostamente intencionava escrever uma segunda parte de Les Illuminés que teria o título "Précurseurs du socialisme" e tematizaria realmente o socialismo através de retratos de Proudhon e Saint-Simon, como mostra sua correspondência com seus editores, esta interpretação imediata deveria ser repensada, pois os illuminés de Nerval não podem ser considerados politicamente socialistas. Entretanto, pode-se levar em conta a hipótese de um socialismo mais literário do que político, ou seja, de uma socialização da literatura.

\section{REFERÊNCIAS BIBLIOGRÁFICAS}

BONY, Jacques. “Nerval: apprenti imprimeur?". Aspects de Nerval: histoire - esthétique fantaisie. Paris: Eurédit, 2006.

. L'esthétique de Nerval. Paris: Euredit, 2004.

Le récit nervalien. Paris: E. José Corti, 1990.

BRIX, Michel. "Les Illuminés de Nerval, ou «le livre parfaitement sensé sur des folies», Nápoles: Studi Francesi, Vol. 34 n. 102, 1990, p. 464-471.

CHOTARD, Loïc (Hrsg.). Nerval. Paris: Presses de l’Université de Paris-Sorbonne, 1997.

DESTRUEL, Philippe. L'écriture nervalienne du temps: l'expérience de la temporalité dans l'œuvre de Gérard de Nerval. Saint-Genouph: Librairie Nizet, 2004.

EGELHAAF-WAGNER, Martina. Autobiografie. Stuttgart: J. B. Metzler Verlag, 2005.

FOUCAULT, Michel. Dits et écrits 1954-1968, org. DEFERT, D./ EWALD, F. , Paris: Vol. 4, 1954 .

. Les mots et les choses. Paris: Gallimard, 1966.

. Archéologie du savoir, Paris: Gallimard, 1969.

. "Des espaces autres (conférence au Cercle d'études architecturales, 14 mars 1967)".

Dits et écrits in Architecture, Mouvement, Continuité, $\mathrm{n}^{\circ}{ }_{5}, 1984$.

GAUTIER, Théophile. La vie de Gérard. Paris: Éditions Allia, 2010.

ILLOUZ, Jean-Nicolas. "Les religions de Nerval". Savoirs en récit II. Éclats de savoir : Balzac, Nerval, Flaubert, Verne, les Goncourt. Paris : PUV, Paris, 2010, p. 49-69. . Nerval, le ,rêveur en prose'. Imaginaire et écriture. Paris: PUF, 1997.

KAWANO, Marta. Gérard de Nerval: a escrita em trânsito, Cotia: Ateliê Editorial, 2009.

KRISTEVA, Julia. Sèmiôtikè. Recherches sur une sémanalyse. Paris: Seuil, 1969.

KÜPPER, Joachim. "Erlebnis und Dichtung in Nervals Voyage en Orient”, in INGENSCHAY, Dieter e PFEIFFER, Helmut (org.). Werk und Diskurs. Karlheinz Stierle zum 6o. Geburtstag, Munique: Wilhelm Fink Verlag, 1999. 
194 - Remate de Males 31.1-2

MARIE, Aristide, “Gérard de Nerval et l'illuminisme”: Préface aux Illuminés, Récits et portraits. Paris: Honoré Champion, 1929.

MILNER, Max. ,Les Illuminés' de Nerval, ou le livre parfaitement sensé sur des folies. Turim: Studi Francesi, 1990.

NERVAL, Gérard de. Euvres Complètes, Volumes I, II, II. Paris: Gallimard, 1984.

PICHOIS, Claude e BRIX, Michel. Gérard de Nerval. Paris: Fayard, 1995.

RICHER, Jean. Gérard de Nerval et les doctrines ésotériques. Paris: Le Griffon d'or, 1947.

RIGOLI, Jean. Lire le délire, Aliénisme, rhétorique et littérature en France au XIXe siècle. Paris: Fayard, 2001.

SCHAEFFER, Gérald. Une double lecture de Gérard de Nerval. Neuchâtel: À la Baconnière (entre outras), 1977.

SCHNEIDER, Michel. Voleurs de mots, Paris: Gallimard, 1985.

STREIFF MORETTI, Monique. Nerval: l’autre discours. Nápoles: Ed. Scientifiche Italiane, 1991. . Monique. "Portraits dans une bibliothèque. Nerval, Toepffer et quelques autres". Paris: Cahiers Gérard de Nerval, N $5,1982$.

TSUJIKAWA, Keiko. Nerval et les limbes de l'histoire. Genève: Droz, 2008.

TYERS, Meryl. Critical fictions: Nerval's Les Illuminés. Oxford: Legenda, 1998.

WARNING, Rainer. Heterotopien als Räume ästhetischer Erfahrung. Munique: Fink, 2009.

. Die Phantasien der Realisten. Munique: Fink, 1999.

\section{Dicionários e enciclopédias}

Le Littré : Le dictionnaire de la langue française. Paris : Garnier, 2007.

Metzler-Lexikon Literatur. Stuttgart e Weimar : Ed. J. B. Metzler, 2007. 